\title{
Cardiovascular actions of angiotensin-(1-7)
}

A.J. Ferreira ${ }^{1,2}$ and R.A.S. Santos ${ }^{1}$
1Departamento de Fisiologia e Biofísica, 2Departamento de Morfologia, Instituto de Ciências Biológicas, Universidade Federal de Minas Gerais, Belo Horizonte, MG, Brasil

\author{
Correspondence \\ R.A.S. Santos \\ Departamento de Fisiologia e \\ Biofísica, ICB, UFMG \\ Av. Antônio Carlos, 6627 \\ 31270-901 Belo Horizonte, MG \\ Brasil \\ Fax: +55-31-3499-2924 \\ E-mail: marrob@ciclope.lcc.ufmg.br \\ Presented at the VIII Brazilian \\ Symposium on Cardiovascular \\ Physiology, São Paulo, SP, Brazil, \\ June 4-6, 2004. \\ Research supported in part by \\ CNPq-PRONEX (Programa de Grupos \\ de Excelência) and CAPES.
}

Received September 22, 2004 Accepted February 25, 2005

\begin{abstract}
Angiotensin-(1-7) (Ang-(1-7)) is now considered to be a biologically active member of the renin-angiotensin system. The functions of Ang(1-7) are often opposite to those attributed to the main effector component of the renin-angiotensin system, Ang II. Chronic administration of angiotensin-converting enzyme inhibitors (ACEI) increases 10- to 25-fold the plasma levels of this peptide, suggesting that part of the beneficial effects of ACEI could be mediated by Ang-(1-7). Ang(1-7) can be formed from Ang II or directly from Ang I. Other enzymatic pathways for Ang-(1-7) generation have been recently described involving the novel ACE homologue ACE2. This enzyme can form Ang-(1-7) from Ang II or less efficiently by the hydrolysis of Ang I to Ang-(1-9) with subsequent Ang-(1-7) formation. The biological relevance of Ang-(1-7) has been recently reinforced by the identification of its receptor, the G-protein-coupled receptor Mas. Heart and blood vessels are important targets for the formation and actions of Ang-(1-7). In this review we will discuss recent findings concerning the biological role of Ang-(1-7) in the heart and blood vessels, taking into account aspects related to its formation and effects on these tissues. In addition, we will discuss the potential of Ang-(1-7) and its receptor as a target for the development of new cardiovascular drugs.
\end{abstract}

\section{Introduction}

The renin-angiotensin system (RAS) is a major regulator of renal and cardiovascular function, playing a pivotal role in the homeostasis of arterial pressure and of the hydroelectrolyte balance. In the past few years the combination of classical physiopharmacological techniques with modern genomics and protein chemistry methods has led to the identification of many novel components of the RAS: the angiotensin (Ang) IV binding site insulin-regulated aminopeptidase (1), angiotensin-converting enzyme 2 (ACE2)
$(2,3)$, the renin receptor (4), and the Ang-(17) receptor Mas (5). Recent reports have also suggested that Des-Asp ${ }^{1}$-Ang I (Ang-(2-10)) has cardiovascular actions which may be direct or depend on its processing to smaller peptides (6). Ang-(1-7) is one of the most interesting peptide fragments of the RAS because it can be formed directly from Ang I independent of ACE (Figure 1) and because it has actions which are often opposite to those of Ang II (7). The recent identification of the Ang-(1-7)-forming enzyme ACE2 and of Mas as an Ang-(1-7) receptor has added further support and wider acceptance (8-10) 
Figure 1. Schematic representation of the enzymatic pathways involved in the generation of angiotensin peptides. Ang-(1-7) can be formed by at least three different pathways: directly from Ang I by NEP and PEP, by hydrolysis of Ang II by PCP, PEP, and ACE2, and finally by hydrolysis of Ang-(1-9) by ACE and NEP. Ang-(1-7) is metabolized mainly by ACE to the inactive fragment Ang-(1-5). ACE = angiotensinconverting enzyme; Ang = angiotensin; $\mathrm{AMP}=$ aminopeptidase; $\mathrm{AT}_{1}=$ Ang II type 1 receptor; $\mathrm{AT}_{2}=$ Ang II type 2 receptor; $A T_{1-7}=$ Ang-(1-7) receptor Mas; $\mathrm{D}-\mathrm{Amp}=$ dipeptidyl-aminopeptidase; IRAP = insulin-regulated aminopeptidase; $\mathrm{PCP}=$ prolylcarboxypeptidase; $\mathrm{PEP}=$ prolyl endopeptidase; NEP $=$ neutralendopeptidase 24.11. to a new concept of the RAS, formally supported by several groups (7,11-13). According to this novel concept, the RAS has two major types of action, each using a different RAS peptide: a vasoconstrictor/proliferative one in which the major player is Ang II and a vasodilator/anti-proliferative one in which the major effector is Ang-(1-7). A further layer of complexity in this concept is represented by the $\mathrm{AT}_{2}$-mediated actions which are often opposite to those elicited by activation of $\mathrm{AT}_{1}$ receptors (9), and possibly involves interaction with the $\mathrm{AT}_{1-7}$ receptor Mas (14). Thus, the dual effects of the RAS can be ascribed to its peptides (mainly Ang II $v s$ Ang-(1-7)) as well as to their receptors (mainly $\mathrm{AT}_{1}$ vs $\mathrm{AT}_{2}+$ Mas) (Table 1). In this article, we will briefly review novel aspects related to the cardiovascular actions of Ang-
(1-7), focusing on the possible physiological role of the ACE2-Ang-(1-7)-Mas axis.

\section{Ang-(1-7) formation and actions in the heart}

Recent reports have indicated heart and blood vessels as the main targets for the actions of Ang-(1-7). These actions include biochemical and functional alterations leading to vasodilation and improved cardiac function (15-17). Several studies suggest that the heptapeptide Ang-(1-7) has beneficial cardiovascular effects either directly or indirectly through bradykinin (BK) potentiation or by counter-regulation of the actions of Ang II (7). The presence and local generation of Ang-(1-7) in the myocardium was first reported by Santos et al. (18) in the

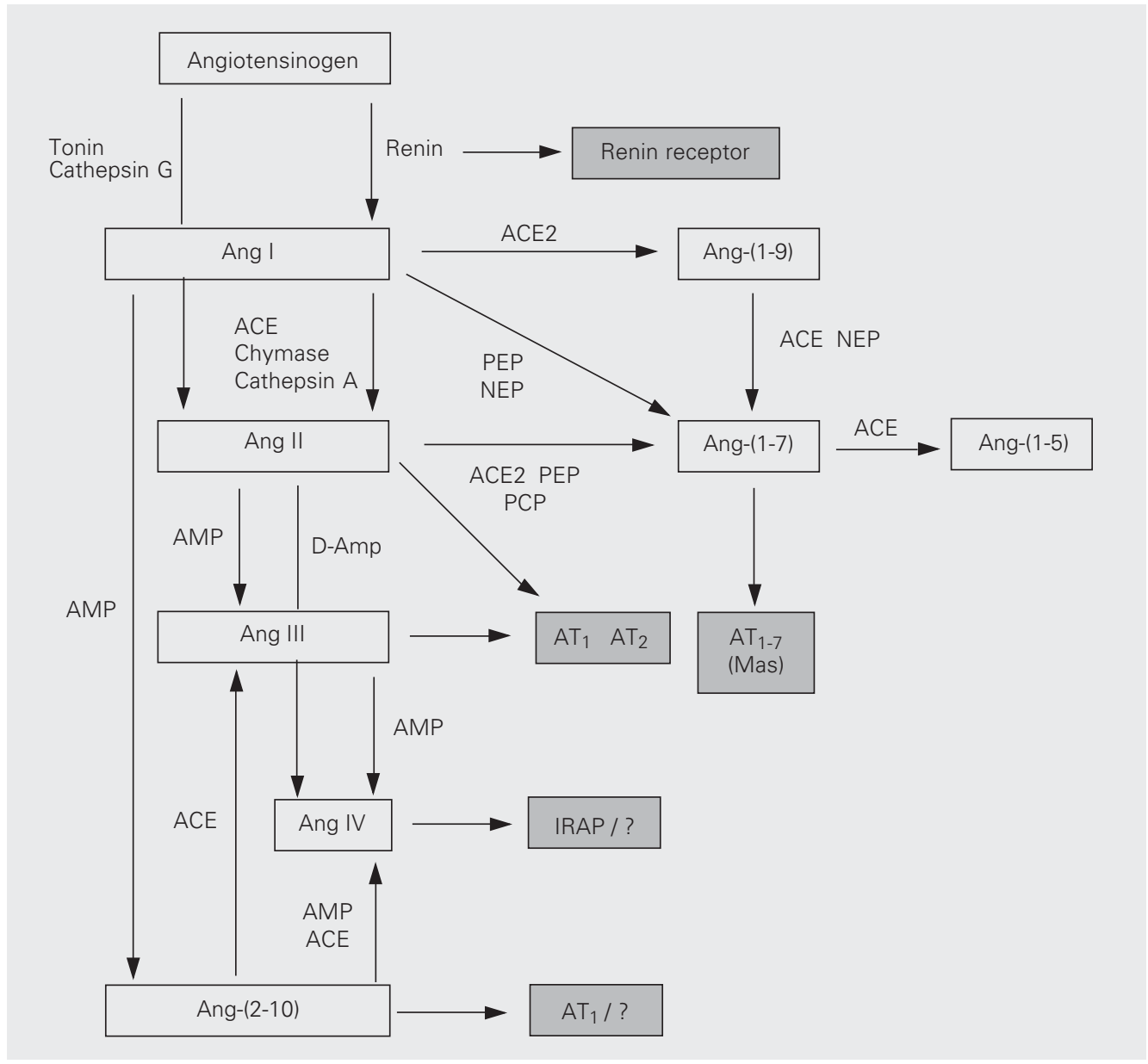


canine heart. In that study, immunoreactive Ang-(1-7) was demonstrated in the aortic root, coronary sinus, and right atrium under basal conditions. Ang-(1-7) was markedly reduced following treatment with the $\mathrm{ACE}$ inhibitor CGS-14,831 (18). In isolated rat hearts, Ang I is extensively metabolized during a single pass through the coronary bed, leading to the generation of Ang II, Ang III, Ang IV, and Ang-(1-7) (19,20). Ang-(1-7) formation in this model was not significantly changed by ACE inhibitors (19). Ang-(1-7) is also formed in the intact human myocardial circulation but, in contrast to the rat heart, ACE inhibitors markedly decrease Ang-(1-7) generation (21).

A novel ACE homologue (ACE2) was described a few years ago $(2,3)$. ACE2 can form Ang-(1-7) from Ang II (22) or less efficiently by hydrolysis of Ang I to Ang-(19) $(3,10,22)$ with subsequent Ang-(1-7) generation by ACE and neprilysin hydrolysis (23). ACE2 is expressed extensively in the heart but is also located in the endothelium (22). Recent studies have indicated that ACE2 is an important regulator of the RAS and apparently plays an important role in heart function (10,24). Interestingly, heart ACE2 is increased by treatment with $\mathrm{AT}_{1}$ antagonists and in failing human heart ventricles $(25,26)$. Averill et al. (27) reported that Ang(1-7) immunoreactivity was limited to cardiac myocytes and absent in interstitial cells and vessels. Myocardial infarction induced by left coronary artery occlusion significantly increased Ang-(1-7) immunoreactivity in the ventricular tissue surrounding the infarcted area. These studies suggest that Ang(1-7) is part of a functional RAS in the heart.

Concerning the effects of Ang-(1-7) in the coronary bed there are marked differences related to dose and species. In isolated canine coronary artery rings precontracted with the thromboxane $\mathrm{A}_{2}$ analogue U46,619, Ang-(1-7) elicited a dose-dependent vasorelaxation (10 nM to $100 \mu \mathrm{M})$. This effect was completely blocked by the nonselective Ang II antagonist $\left(\mathrm{Sar}^{1}, \mathrm{Thr}^{8}\right)$-Ang II, but not by the selective $\mathrm{AT}_{1}$ or $\mathrm{AT}_{2}$ Ang II antagonists CV11974 and PD123319, respectively, sug-

\begin{tabular}{|c|c|c|}
\hline Angiotensin & Receptor & Actions \\
\hline Ang II & $\mathrm{AT}_{1}$ & $\begin{array}{l}\text { Vasoconstriction and pressor effect } \\
\text { Increase of inotropism and chronotropism } \\
\text { Arrhythmogenic effect } \\
\text { Remodeling and cell proliferation } \\
\text { Thrombosis and inflammation }\end{array}$ \\
\hline Ang II & $\mathrm{AT}_{2}$ & $\begin{array}{l}\text { Inhibition of cell proliferation } \\
\text { Apoptosis } \\
\text { Vasodilation (?) }\end{array}$ \\
\hline Ang-(1-7) & $A T_{1-7}(\mathrm{Mas})^{*}$ & $\begin{array}{l}\text { Vasodilation } \\
\text { Potentiation of BK-induced vasodilation } \\
\text { Anti-arrhythmogenic effect } \\
\text { Improvement of post-ischemic contractile function } \\
\text { Inhibition of cell proliferation }\end{array}$ \\
\hline Ang-(3-8) (Ang IV) & $\mathrm{AT}_{4}(\mathrm{IRAP}) / ?$ & $\begin{array}{l}\text { Vasodilation } \\
\text { Inhibition of cell proliferation }\end{array}$ \\
\hline Des-Asp ${ }^{1}$-Ang I & $\mathrm{AT}_{1} / ?$ & Inhibition of Ang II-induced cell proliferation \\
\hline
\end{tabular}

*Mas-mediated actions were listed based on direct or indirect evidence (blocked by A-779). Ang = angiotensin; BK = bradykinin; IRAP = insulin-regulated aminopeptidase. 
gesting the existence of a specific ligand site for Ang-(1-7) in dog coronary vessels (15). Moreover, the vasorelaxant activity of Ang-
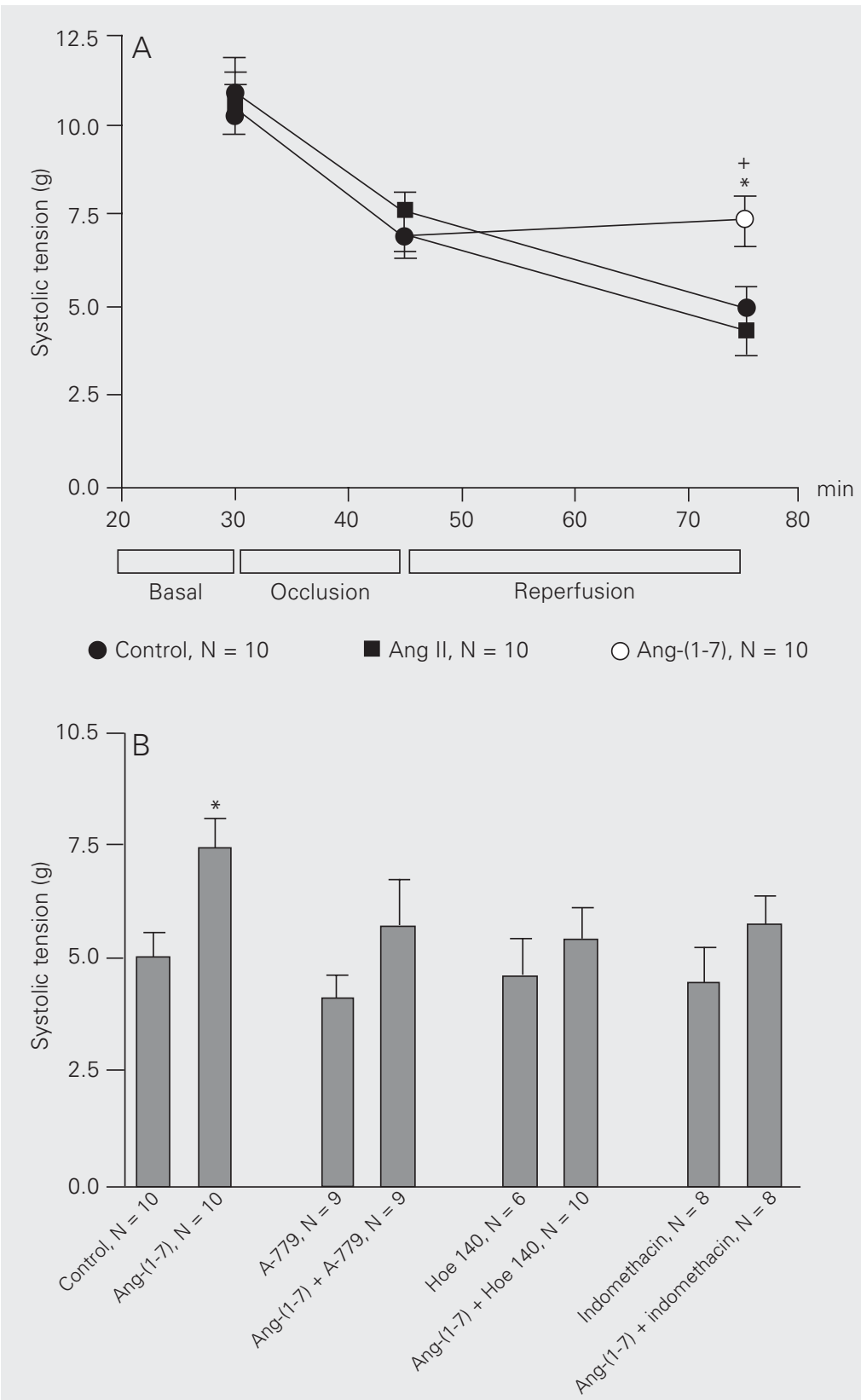

Figure 2. Time course of changes in systolic tension in isolated perfused rat heart submitted to temporary coronary occlusion. The hearts were perfused with Krebs-Ringer solution (KRS, control), KRS containing $0.22 \mathrm{nM}$ angiotensin (Ang)-(1-7), or KRS containing $0.20 \mathrm{nM}$ Ang II. The systolic tension was preserved in hearts perfused with Ang-(1-7) in the reperfusion period (A). This effect was completely blocked by A-779 (2 nM), Hoe 140 (100 $\mathrm{nM})$, and pretreatment with indomethacin (5 mg/ $/ \mathrm{kg}, i p, 1 \mathrm{~h}$ before heart removal) (B). ${ }^{*} \mathrm{P}<$ 0.05 compared to the control group and $+P<0.05$ compared to the Ang II group (Student $t$ test).
(1-7) was markedly attenuated by the nitric oxide (NO) synthase inhibitor L-NA and by the specific kinin $\mathrm{B}_{2}$ receptor blocker Hoe 140 , but not by the cyclooxygenase inhibitor indomethacin (15). On the other hand, Neves et al. (28) found that Ang-(1-7) induced a concentration-dependent $(27,70$, and 210 $\mathrm{nM})$ decrease in coronary flow in isolated perfused rat hearts, and effect that was not accompanied by consistent changes in inotropism or heart rate. A similar result was observed in isolated hamster hearts (29).

According to Loot et al. (17), chronic infusion (8 weeks) of Ang-(1-7) improved endothelial aortic function and coronary perfusion and preserved cardiac function in an experimental rat model of heart failure induced by ligation of the left coronary artery. The vascular endothelial dysfunction observed in aortic rings from rats with myocardial infarction was also markedly reversed by chronic infusion of Ang-(1-7) (17). The mechanisms of the coronary vascular actions of Ang-(1-7) have not been fully characterized, but probably involve release of prostacyclin and/or NO (11). One possible pathway involved in the coronary effects of Ang-(1-7) is the amplification of the vasodilator effects of BK. The vasodilator effect produced by BK injected in bolus into isolated perfused rat hearts or into isolated canine coronary arteries was potentiated by Ang-(1-7) (15,30).

Ang-(1-7) produced a significant increase in cardiac output and stroke volume in anesthetized Wistar rats as assessed by a fluorescent microsphere methodology. These effects were partially attenuated by the Ang(1-7) antagonist, A-779 (31). We have shown that Ang-(1-7) at $220 \mathrm{pM}$ concentration decreased the incidence and duration of ischemia-reperfusion arrhythmias in isolated perfused rat hearts (16). These cardioprotective effects were blocked by A-779 and by the cyclooxygenase inhibitor indomethacin. Furthermore, at the same low concentration, Ang-(1-7) improved the post-ischemic con- 
tractile function in isolated perfused rat hearts by a mechanism apparently involving its receptor Mas (5) and release of BK and prostaglandins (Figure 2) (32). Of note is the fact that at higher concentration $(27 \mathrm{nM})$ Ang-(1-7) exerts an opposite effect. Neves et al. (28) reported that Ang-(1-7) facilitated reperfusion arrhythmias in isolated perfused rat hearts. Accordingly, transgenic mice overexpressing ACE2 in the heart presented sudden death due to cardiac arrhythmias (33). These observations suggest that high local concentrations of Ang-(1-7) have deleterious effects on the heart.

Using the engineered fusion protein strategy, we have generated a transgenic rat model expressing an Ang-(1-7)-producing fusion protein (34). These TGR(A1-7)3292 rats presented a 2.5 -fold increase in plasma Ang-(1-7) concentration. Radiotelemetry measurements showed that transgenic rats presented a slight but significant increase in diurnal and nocturnal $\mathrm{dP} / \mathrm{dt}$ measurements. TGR(A1-7)3292 rats were significantly more resistant than control animals to induction of cardiac hypertrophy by isoproterenol. Moreover, these transgenic rats showed a reduced duration of reperfusion arrhythmias and an improved post-ischemic function in isolated perfused hearts. Therefore, this model provided further evidence for an important role of Ang-(1-7) in cardiac function (34).

\section{Ang-(1-7) formation and actions in blood vessels}

Endothelial cells are an important site for the formation (35) and metabolism (36) of Ang-(1-7). It has been shown that Ang-(1-7) produces relaxation in several vascular beds, including canine and porcine coronary arteries, canine middle cerebral artery, piglet pial arterioles, feline systemic vasculature, rabbit renal afferent arterioles, rat aortic rings, and mesenteric microvessels of normotensive and hypertensive rats $(37,38$; see also Ref. 7 for a review). In human vessels, con- tradictory results have been reported. Sasaki and co-workers (39) reported vasodilation in the human forearm while Davie and McMurray (40) did not observe any effect of Ang-(1-7) in the same territory in ACEItreated patients. In keeping with previous reports by Ferrario's group (41), a role for Ang-(1-7) in mediating the chronic hypotensive effect of losartan in normal rats has been proposed by Collister and Hendel (42).

Many studies have shown that the vascular actions of Ang-(1-7) appear to involve increased production of vasodilatory prostanoids, NO and endothelium-derived hyperpolarizing factor $(15,43,44)$. Moreover, some vascular effects involve simultaneous participation of these vasodilator mediators. A crosstalk between $\mathrm{AT}_{1-7}$ and other receptors such as kinin $\mathrm{B}_{2}$ and $\mathrm{AT}_{2}$ receptors may also activate these pathways in blood vessels. For example, it has been demonstrated that the vasodilator action of Ang-(1-7) can be blocked by the $\mathrm{B}_{2}$ receptor antagonist Hoe $140(7,15)$. Moreover, a recent study showed that the link between Ang II and BK in endothelium-dependent vasorelaxation could involve receptors that bind the $\mathrm{AT}_{2}$ and Ang(1-7) receptor antagonists, PD123319 and A-779, respectively (45). The participation of vasodilating prostanoids in the vascular actions of Ang-(1-7) is not restricted to vasorelaxation, since they are also apparently involved in the antiproliferative actions of Ang-(1-7) in vascular smooth muscle cells and cardiomyocytes $(44,46)$. Recently, it has been demonstrated that Ang-(1-7) inhibits vascular growth by the production of prostaglandin-mediated intracellular events, which include cAMP production and reduction of Ang II-stimulated ERK1/2 activities (47).

An important subset of cardiovascular actions of Ang-(1-7) is related to its BKpotentiating activity. Ang-(1-7) potentiates the vasodilator and hypotensive effects of BK in normotensive (48) and hypertensive (38) rats, in the human forearm (49), and in porcine (50), dog (15) and rat coronary 
vessels (30). As mentioned above for vasodilation, the BK-potentiating activity of Ang-(1-7) is controversial in humans. Ueda et al. (49) reported BK potentiation while Wilsdorf et al. (51) were unable to show an effect at supraphysiological doses. Several mechanisms have been proposed to explain the BK-potentiating activity of Ang-(1-7) including ACE inhibition (50), non-hydrolytic interaction with ACE favoring a crosstalk between ACE and the BK- $\mathrm{B}_{2}$ receptor (52), and $\mathrm{AT}_{1-7}$ receptor-mediated changes in the coupling and/or signaling of $\operatorname{BK}(7,16,38,48)$. The recent observation that the Ang-(1-7) antagonist D-Ala ${ }^{7}$-Ang-(1-7) reverses the potentiation of $\mathrm{BK}$ in mesenteric microvessels by enalapril or enalaprilat (38) or attenuates the potentiated hypotensive response to BK in captopril-treated rats (53) indicates that an Ang-(1-7)-related mechanism is importantly involved in the effects of ACEI. In addition, the vascular actions of Ang-(1-7) could involve modulation of Ang II-induced changes in vascular resistance $(13,54)$.

\section{Ang-(1-7) and its receptor in the heart and blood vessels}

Many of the cardiovascular effects of Ang-(1-7) are completely blocked by the selective Ang-(1-7) antagonist A-779, suggesting that the effects of Ang-(1-7) on the heart and blood vessels are mediated by a specific receptor sensitive to A-779 (16,3032,37,38; see also Ref. 7 for a review). Recently, Santos et al. (5) reported that Ang-(17) is an endogenous ligand for the G-proteincoupled receptor Mas. The specific binding of ${ }^{125}$ I-Ang-(1-7) in mouse kidney slices was abolished by genetic deletion of Mas while the binding of ${ }^{125} \mathrm{I}$-Ang II and ${ }^{125} \mathrm{I}$-Ang IV was fully preserved. Furthermore, ${ }^{125}$ I-Ang(1-7) bound with high affinity to Mas-transfected COS cells and Ang-(1-7) treatment elicited arachidonic acid release from $\mathrm{CHO}$ and COS cells transfected with the Mas re- ceptor. The binding of ${ }^{125} \mathrm{I}$-Ang-(1-7) and the effect of Ang-(1-7) on arachidonic acid release were blocked by the Ang-(1-7) antagonist A-779. Mas mRNA was detected in the heart, testis, kidney, and brain (55). In keeping with the putative cardioprotective role of Ang-(1-7), isolated hearts of Masdeficient mice presented marked changes in cardiac function. The systolic tension and positive and negative $\mathrm{dT} / \mathrm{dt}$ were importantly decreased. Furthermore, a significant decrease in heart rate and an increase in coronary vascular resistance were also observed (56). In addition, the left ventricular pressure, positive $\mathrm{dP} / \mathrm{dt}$, and cardiac output were significantly lower in Mas-knockout mice assessed by means of a micro-conductance catheter placed inside the left ventricle (57). A reduced heart rate variability associated with an increased sympathetic tone was also found in Mas-deficient animals (58). These findings indicate that the Ang-(1-7) receptor Mas plays an important role in cardiac function and that the interaction of Ang-(1-7) with its specific receptor Mas is an important step for the actions of this peptide in the heart.

Evidence for a role of the Ang-(1-7) receptor Mas in the vascular effects of Ang-(17) was also obtained. Experiments on aortic rings derived from Mas-deficient mice demonstrated that the Ang-(1-7)-induced endothelium- dependent relaxation was abolished (5). This observation agrees with the results observed in Mas-transfected CHO cells, where Ang-(1-7), as well as its non-peptide agonist, AVE 0991 (59), cause a concentration-dependent increase in NO release (14). This effect was also blocked by A-779 but not by $\mathrm{AT}_{1}$ or $\mathrm{AT}_{2}$ antagonists. The Mas receptor appears to be also involved in the antiproliferative effect of Ang-(1-7) in vascular smooth muscle cells (47). It should be pointed out that, besides a Mas-Ang-(1-7) interaction, other mechanisms may be involved in the Ang-(1-7) vasodilatory effect, depending on the vessel diameter and the vascular regional bed (31). 


\section{Perspectives}

Considering our current knowledge of the actions of Ang-(1-7), we could divide its cardiovascular actions into Mas-mediated and non-Mas-mediated ones. The fact that some actions of Ang-(1-7) are also blocked by $\mathrm{AT}_{1}$ or $\mathrm{AT}_{2}$ antagonists $(7,11,60)$ is in favor of this hypothesis and may represent an indirect interaction of Ang-(1-7) with $\mathrm{AT}_{1}$ and $\mathrm{AT}_{2}$ receptors via Mas. In addition, the possibility of Ang-(1-7) directly interacting with $\mathrm{AT}_{1}$ or $\mathrm{AT}_{2}$ receptors as it does with
ACE $(7,53)$, cannot be excluded, especially at high Ang-(1-7) concentrations. The availability of non-peptide Ang-(1-7) receptor agonists, such as AVE 0991 (59), is a novel and important tool that will permit us to better understand its biological role and to clarify its complex mechanism of action (14). More importantly, these drugs may represent a new possibility for the development of novel therapeutic strategies for the treatment of cardiovascular diseases by interfering with the ACE2-Ang-(1-7)-Mas axis.

\section{References}

1. Albiston AL, McDowall SG, Matsacos D et al. (2001). Evidence that the angiotensin IV (AT(4)) receptor is the enzyme insulin-regulated aminopeptidase. Journal of Biological Chemistry, 276: 48623-48626.

2. Tipnis SR, Hooper NM, Hyde R, Karran E, Christie G \& Turner AJ (2000). A human homolog of angiotensin-converting enzyme. Cloning and functional expression as a captopril-insensitive carboxypeptidase. Journal of Biological Chemistry, 275: 33238-33243.

3. Donoghue M, Hsieh F, Baronas E et al. (2000). A novel angiotensinconverting enzyme-related carboxypeptidase (ACE2) converts angiotensin I to angiotensin 1-9. Circulation Research, 87: E1-E9.

4. Nguyen G, Delarue F, Berrou J, Rondeau E \& Sraer JD (1996). Specific receptor binding of renin on human mesangial cells in culture increases plasminogen activator inhibitor-1 antigen. Kidney International, 50: 1897-1903.

5. Santos RAS, Simões e Silva AC, Maric $C$ et al. (2003). Angiotensin(1-7) is an endogenous ligand for the $G$ protein-coupled receptor Mas. Proceedings of the National Academy of Sciences, USA, 100: 8258-8263.

6. Wen Q, Sim MK \& Tang FR (2004). Reduction of infarct size by orally administered des-aspartate-angiotensin I in the ischemic reperfused rat heart. Regulatory Peptides, 120: 149-153.

7. Santos RAS, Campagnole-Santos MJ \& Andrade SP (2000). Angiotensin-(1-7): an update. Regulatory Peptides, 91: 45-62.

8. Schmaier AH (2003). The kallikrein-kinin and the renin-angiotensin systems have a multilayered interaction. American Journal of Physiology, 285: R1-R13.

9. Carey RM \& Siragy HM (2003). Newly recognized components of the renin-angiotensin system: potential roles in cardiovascular and renal regulation. Endocrine Reviews, 24: 261-271.

10. Burrell LM, Johnston Cl, Tikellis C \& Cooper ME (2004). ACE2, a new regulator of the renin-angiotensin system. Trends in Endocrinology and Metabolism, 15: 166-169.

11. Ferrario CM (2002). Does angiotensin-(1-7) contribute to cardiac adaptation and preservation of endothelial function in heart failure? Circulation, 105: 1523-1525.

12. Campbell DJ (2003). The renin-angiotensin and the kallikrein-kinin systems. International Journal of Biochemistry and Cell Biology, 35: 784-791.
13. Roks AJ, van Geel PP, Pinto YM, Buikema $H$, Henning $R H$, de Zeeuw D \& van Gilst WH (1999). Angiotensin-(1-7) is a modulator of the human renin-angiotensin system. Hypertension, 34: 296-301.

14. Pinheiro SVB, Simões e Silva AC, Sampaio WO et al. (2004). Nonpeptide AVE 0991 is an angiotensin-(1-7) receptor Mas agonist in the mouse kidney. Hypertension, 44: 490-496.

15. Brosnihan KB, Li P \& Ferrario CM (1996). Angiotensin-(1-7) dilates canine coronary arteries through kinins and nitric oxide. Hypertension, 27 (Part 2): 523-528.

16. Ferreira AJ, Santos RAS \& Almeida AP (2001). Angiotensin-(1-7): cardioprotective effect in myocardial ischemia/reperfusion. Hypertension, 38 (Part 2): 665-668.

17. Loot $A E$, Roks AJM, Henning RH, Tio RA, Suurmeijer $A J H$, Boomsma F \& van Gilst WH (2002). Angiotensin-(1-7) attenuates the development of heart failure after myocardial infarction in rats. Circulation, 105: 1548-1550.

18. Santos RAS, Brum JM, Brosnihan KB \& Ferrario CM (1990). The renin-angiotensin system during acute myocardial ischemia in dogs. Hypertension, 15 (Suppl): I-121-I-127.

19. Neves LA, Almeida AP, Khosla MC \& Santos RAS (1995). Metabolism of angiotensin I in isolated rat hearts. Effect of angiotensin converting enzyme inhibitors. Biochemical Pharmacology, 50: 14511459.

20. Mahmood A, Jackman HL, Teplitz L \& Igic R (2002). Metabolism of angiotensin I in the coronary circulation of normal and diabetic rats. Peptides, 23: 1171-1175.

21. Zisman LS, Meixell GE, Bristow MR \& Canver CC (2003). Angiotensin-(1-7) formation in the intact human heart: in vivo dependence on angiotensin II as substrate. Circulation, 108: 1679-1681.

22. Vickers C, Hales P, Kaushik V et al. (2002). Hydrolysis of biological peptides by human angiotensin-converting enzyme-related carboxypeptidase. Journal of Biological Chemistry, 277: 14838-14843.

23. Rice GI, Thomas DA, Grant PJ, Turner AJ \& Hooper NM (2004). Evaluation of angiotensin converting enzyme (ACE), its homologue ACE2 and neprilysin in angiotensin peptide metabolism. Biochemical Journal, 383 (Part 1): 45-51.

24. Crackower MA, Sarao R, Oudit GY et al. (2002). Angiotensin-converting enzyme 2 is an essential regulator of heart function. Nature, 
417: 822-828.

25. Zisman LS, Keller RS, Weaver B, Lin Q, Speth R, Bristow MR \& Canver CC (2003). Increased angiotensin-(1-7)-forming activity in failing human heart ventricles: evidence for up regulation of the angiotensin-converting enzyme homologue ACE2. Circulation, 108: 1707-1712.

26. Goulter AB, Goddard MJ, Allen JC \& Clark KL (2004). ACE2 gene expression is up-regulated in the human failing heart. BMC Medicine, 2: 19.

27. Averill DB, Ishiyama Y, Chappell MC \& Ferrario CM (2003). Cardiac angiotensin-(1-7) in ischemic cardiomyopathy. Circulation, 106: 2141-2146.

28. Neves LAA, Almeida AP, Khosla MC, Campagnole-Santos MJ \& Santos RAS (1997). Effect of angiotensin-(1-7) on reperfusion arrhythmias in isolated rat hearts. Brazilian Journal of Medical and Biological Research, 30: 801-809.

29. Kumagai H, Khosla M, Ferrario C \& Fouad-Tarazi FM (1990). Biological activity of angiotensin-(1-7) heptapeptide in the hamster heart. Hypertension, 15 (Suppl): I-29-I-33.

30. Almeida AP, Frábregas BC, Madureira MM, Santos RJS, Campagnole-Santos MJ \& Santos RAS (2000). Angiotensin-(1-7) potentiates the coronary vasodilatory effect of bradykinin in the isolated rat heart. Brazilian Journal of Medical and Biological Research, 33: 709713.

31. Sampaio WO, Nascimento AA \& Santos RAS (2003). Systemic and regional hemodynamic effects of angiotensin-(1-7) in rats. American Journal of Physiology, 284: H1985-H1994.

32. Ferreira AJ, Santos RAS \& Almeida AP (2002). Angiotensin-(1-7) improves the post-ischemic function in isolated perfused rat hearts. Brazilian Journal of Medical and Biological Research, 35: 10831090.

33. Donoghue M, Wakimoto $H$, Maguire CT et al. (2003). Heart block, ventricular tachycardia, and sudden death in ACE2 transgenic mice with downregulated connexins. Journal of Molecular and Cellular Cardiology, 35: 1043-1053.

34. Santos RAS, Ferreira AJ, Nadu AP, Braga ANG, Almeida AP, Campagnole-Santos MJ, Baltatu O, lliescu R, Reudelhuber TL \& Bader M (2004). Expression of an angiotensin-(1-7)-producing fusion protein produces cardioprotective effects in rats. Physiological Genomics, 17: 292-299.

35. Santos RAS, Brosnihan KB, Jacobsen DW, DiCorleto PE \& Ferrario CM (1992). Production of angiotensin-(1-7) by human vascular endothelium. Hypertension, 19 (Suppl): II-56-II-61.

36. Chappell MC, Pirro NT, Sykes A \& Ferrario CM (1998). Metabolism of angiotensin-(1-7) by angiotensin-converting enzyme. Hypertension, 31 (Part 2): 362-367.

37. Ren Y, Garvin JL \& Carretero OA (2002). Vasodilator action of angiotensin-(1-7) on isolated rabbit afferent arterioles. Hypertension, 39: 799-802.

38. Fernandes L, Fortes ZB, Nigro D, Tostes RCA, Santos RAS \& Carvalho MHC (2001). Potentiation of bradykinin by angiotensin-(17) on arterioles of spontaneously hypertensive rats studied in vivo. Hypertension, 37: 703-709.

39. Sasaki S, Higashi Y, Nakagawa K, Matsuura H, Kajiyama G \& Oshima $T$ (2001). Angiotensin-(1-7) induces endothelium-independent vasodilation in normotensive control subjects and essential hypertensive patients. Hypertension, 38: 90-94.

40. Davie AP \& McMurray JJ (1999). Effect of angiotensin-(1-7) and bradykinin in patients with heart failure treated with an ACE inhibitor. Hypertension, 34: 457-460.

41. Nakamura S, Averill DB, Chappell MC, Diz DI, Brosnihan KB \&
Ferrario CM (2003). Angiotensin receptors contribute to blood pressure homeostasis in salt-depleted SHR. American Journal of Physiology, 284: R164-R173.

42. Collister JP \& Hendel MD (2003). The role of Ang (1-7) in mediating the chronic hypotensive effects of losartan in normal rats. Journal of the Renin-Angiotensin-Aldosterone System, 4: 176-179.

43. Heitsch H, Brovkovych S, Malinsk T \& Wiemer G (2001). Angiotensin-(1-7)-stimulated nitric oxide and superoxide release from endothelial cells. Hypertension, 37: 72-76.

44. Muthalif MM, Benter IF, Uddin MR, Haper JL \& Malik KU (1998). Signal transduction mechanism involved in angiotensin-(1-7)-stimulated arachidonic acid release and prostanoid synthesis in rabbit aortic smooth cells. Journal of Pharmacology and Experimental Therapeutics, 284: 388-398.

45. Soares de Moura R, Resende AC, Emiliano AF, Tano T, MendesRibeiro AC, Correia ML \& Carvalho LC (2004). The role of bradykinin, AT2 and angiotensin 1-7 receptors in the EDRF-dependent vasodilator effect of angiotensin II on the isolated mesenteric vascular bed of the rat. British Journal of Pharmacology, 141: 860-866.

46. Min L, Sim MK \& Xu XG (2000). Effects of des-aspartate-angiotensin I on angiotensin II-induced incorporation of phenylalanine and thymidine in cultured rat cardiomyocytes and aortic smooth muscle cells. Regulatory Peptides, 95: 93-97.

47. Tallant EA, Chappell MC, Ferrario CM \& Gallagher PE (2004). Inhibition of MAP kinase activity by angiotensin-(1-7) in vascular smooth muscle cells is mediated by the Mas receptor. Hypertension, 43: 1348 (Abstract).

48. Paula RD, Lima CV, Khosla MC \& Santos RAS (1995). Angiotensin(1-7) potentiates the hypotensive effect of bradykinin in conscious rats. Hypertension, 26 (Part 2): 1154-1159.

49. Ueda S, Masumori-Maemoto S, Wada A, Ishii M, Brosnihan KB \& Umemura S (2001). Angiotensin(1-7) potentiates bradykinin-induced vasodilatation in man. Journal of Hypertension, 19: 2001-2009.

50. Tom B, de Vries R, Saxena PR \& Danser AH (2001). Bradykinin potentiation by angiotensin-(1-7) and ACE inhibitors correlates with ACE C- and N-domain blockade. Hypertension, 38: 95-99.

51. Wilsdorf T, Gainer JV, Murphey LJ, Vaughan DE \& Brown NJ (2001). Angiotensin-(1-7) does not affect vasodilator or TPA responses to bradykinin in human forearm. Hypertension, 37: 1136-1140.

52. Erdos EG, Jackman HL, Brovkovych V, Tan F \& Deddish PA (2002). Products of angiotensin I hydrolysis by human cardiac enzymes potentiate bradykinin. Journal of Molecular and Cellular Cardiology, 34: 1569-1576.

53. Maia LG, Ramos MC, Fernandes L, Carvalho MH, CampagnoleSantos MJ \& Santos RAS (2004). Angiotensin-(1-7) antagonist A779 attenuates the potentiation of bradykinin by captopril in rats. Journal of Cardiovascular Pharmacology, 43: 685-691.

54. Stegbauer J, Oberhauser V, Vonend O \& Rump LC (2004). Angiotensin-(1-7) modulates vascular resistance and sympathetic neurotransmission in kidneys of spontaneously hypertensive rats. Cardiovascular Research, 61: 352-359.

55. Metzger R, Bader M, Ludwig T, Berberich C, Bunnemann B \& Ganten D (1995). Expression of the mouse and rat mas protooncogene in the brain and peripheral tissues. FEBS Letters, 357: 2732.

56. Castro $\mathrm{CH}$, Santos RAS, Walther T, Alenina N, Bader M \& Almeida AP (2004). Effects of genetic deletion of the G-protein-coupled receptor Mas on cardiac function during ischemia and reperfusion in the mouse isolated perfused heart. Hypertension, 43: 1350 (Abstract).

57. Gembardt F, Westermann D, Heringer-Walther S, Schultheiss HP, 
Tschöpe C \& Walter T (2003). Deficiency in the G protein-coupled receptor Mas leads to cardiomyopathy and demonstrates the importance of the endogenous ligand angiotensin-(1-7) for the cardiac function. Naunyn-Schmiedebergs Archives of Pharmacology, 369 (Suppl 1): R68 (Abstract)

58. Walther T, Wessel N, Kang N, Sander A, Tschöpe C, Malberg H, Bader M \& Voss A (2000). Altered heart rate and blood pressure variability in mice lacking the Mas protooncogene. Brazilian Journal of Medical and Biological Research, 33: 1-9.

59. Wiemer G, Dobrucki LW, Louka FR, Malinski T \& Heitsch H (2002). AVE 0991, a nonpeptide mimic of the effects of angiotensin-(1-7) on the endothelium. Hypertension, 40: 847-852.

60. Gironacci MM, Adler-Graschinsky E, Pena C \& Enero MA (1994). Effects of angiotensin II and angiotensin-(1-7) on the release of $\left.{ }^{3} \mathrm{H}\right)$ norepinephrine from rat atria. Hypertension, 24: 457-460. 